\title{
NORMALIZAR LA EXISTENCIA LESBIANA
}

\author{
Natalia Cabanillas \\ Universidade de Brasília, Distrito Federal, Brasil
}

\begin{abstract}
Resumen: El artículo analiza las resonancias entre el activismo de Free Gender - organización de mujeres negras lesbianas (Khayelitsha, Ciudad del Cabo) y el art-ivismo LGTBI de Zanele Muholi (Sudáfrica). Se abordan qué recursos se utilizan para la producción artesanal (Sophie OLDFIELD; Elaine SALO, 2009) de la existencia lesbiana, su normalización e individuación: por un lado, las participaciones e intervenciones públicas de Free Gender en los espacios comunitarios; y por otro, la producción de retratos y de escenas de intimidad - series fotográficas de Zanele Muholi Faces and Phases y Beloved respectivamente. Por último, se destaca la dimensión subversiva de fundar un archivo LGTBI y contestar el archivo colonial con sus múltiples representaciones estereotipadas de la sexualidad de las mujeres negras.
\end{abstract} Palabras Cloves: Activismo LGTBI; Mujeres negras; Sexualidad; Archivo.

\section{Introducción}

Si no me equivoco, fue en 2010 cuando estábamos en la corte por el caso de Millicent', y Zanele [Muholi] dijo 'necesitamos un blog', y todas nos miramos como diciendo ¿qué carajo es eso? Nosotras no sabíamos qué era esa cosa del blog. Nos dijo, todo lo que ustedes hagan, lo tienen que documentar (Funeka SOLDAAT, 2014, entrevista) ${ }^{2}$.

Uno de los elementos centrales de la políica de la organización de mujeres lesbianas negras $^{3}$, Free Gender Khayelitsha ${ }^{4}$ (Ciudad del Cabo), es documentar la propia lucha desde una política de autorepresentación. Por un lado, estas ideas son parte del universo político de las organizaciones de mujeres, feministas o no; y, por otro lado, este proyecto

\footnotetext{
(C) (D) Esta obra está sob licença Creative Commons.

' Caso judicial (2013) en el que Andile Ngcoza fue condenado por la violación de Millicent Gaika, joven lesbiana de Gugulethu, Ciudad del Cabo (Xolani KOYANA testimonio citado en MUHOLI, 2014, p. 268). ${ }^{2}$ Líder y fundadora de la organización Free Gender Khayelitsha.

${ }^{3}$ Las mujeres involucradas en esta investigación se autodefinen como black o African (negra/africana), dependiendo la circunstancia. Se escoge la categoría negra para referir a los grupos que fueron clasificados por el apartheid como African, que hoy día se autodefinen mayoritariamente como negra/africana. En este trabajo, no incluyo en esta categoría la población autodenominada bruimensen o coloured ni indians, quienes bajo determinadas versiones de la negritud politizada se definieron como Negras.

${ }^{4}$ Khayelitsha es uno de los mayores barrios negros segregados de la periferia de Ciudad del Cabo. El $90 \%$ de la población es xhosa hablante y 95\% negra, ver Ravayi MARINDO, 2008.
} 
concreto se desarrolla a partir del camino recorrido junto con la activista visual Zanele Muholi $^{5}$. En el presente artículo ${ }^{6}$ se analiza el trabajo de Zanele Muholi y sus resonancias con las intervenciones de Free Gender Khayelitsha. La resonancia permite una audibilidad mayor y más placentera: multiplica y desdobla el sonido. Escogí esta palabra para caracterizar la relación política y de amistad que existe entre la artista y la organización, resaltando el carácter político-sensorial: a través de una se comprende - se audibiliza mejor la otra, así, mutuamente.

La art-ivista Zanele Muholi nació y creció en Umlazi, township ${ }^{7}$ negro de Durban. Fue entrenada por el fotoperiodista David Goldblatt, y hoy día posee una extensa carrera artística internacional como fotógrafa, e imparte talleres de fotografía entre la comunidad negra LGTBI. Gran parte de sus proyectos artísticos se enmarcan en la producción masiva del archivo visual de la comunidad negra LGTBI, principalmente en Sudáfrica.

Este emprendimiento resuena en las intervenciones públicas de Free Gender por "el derecho de existir" (Zethu MATEBENI, 2015, entrevista) ${ }^{8}$. Tal lucha se manifiesta en las disputas en torno del Orgullo Gay de Ciudad del Cabo, realizado cada año próximo al centro de la ciudad; y en el Orgullo Khumbulani, localizado en las comunidades negras de la periferia desde hace 3 años.

Dentro de la producción - material o visualmente - de la vida LGTBI se incluye una forma de inscribir esa vida, normalizar su existencia, a través de formas concretas de integración a la vida comunitaria (Free Gender); y la creación de un régimen de visualización que contesta las narrativas visuales de brutalización y victimización de los cuerpos de mujeres lesbianas negras en el país en el trabajo de Zanele Muholi. Dicho lenguaje visual normaliza e individualiza simultáneamente, usa el retrato como recurso discursivo, y la intimidad como un espacio de transgresión. En este plano, Free Gender apuesta a descentrar la sexualidad disidente, restituir la totalidad de la vida y 'cotidianeizar' el ser lesbiana.

\section{Documento, luego existo: el archivo como talismán}

En su artículo The power of the archives and its limits Achille Mbembe (2002, p. 21) definió el archivo como un talismán que proyecta poderes especiales: el de ser reconocido como el espacio y el acervo que contiene pruebas, rastros de una vida pasada. El poder del archivo no estaría en el contenido, tipo o tamaño, sino en su dimensión 'performativa' (Carolyn HAMILTON, 2002, p. 9), a través de la cual dota de existencia a los procesos, instituciones u objetos representados como reales en un acervo en particular. Esa dimensión 'performativa' se asienta sobre un formato particular: la escritura, dispositivo de perdurabilidad, y signo fundante de la soberanía del Estado para administrar, clasificar y ordenar.

Intelectuales africanas 9 investigaron las representaciones de los cuerpos y sexualidades de mujeres negras, inscriptas en relaciones de poder de raíz colonial. Desiree

\footnotetext{
${ }^{5}$ Zanele Muholi es una activista visual de amplia trayectoria, expuso en innúmeras galerías, entre ellas: $55^{\text {th }}$ Bienal de Venecia, Documenta $13,29^{\text {th }}$ Exposición de San Pablo, Les Rencontres d'Arles, Francia. (Zanele MUHOLI, 2014, p. 363)

${ }^{6}$ Este trabajo es un resultado parcial de la investigación de doctorado en curso (PSOL-UnB), Mujeres Activistas en Ciudad del Cabo. El material documental, bibliográfico y de campo fueron posibles gracias a distintas estancias de investigación de 18 meses en total y con los apoyos financieros de FAP-DF, CNPq, PDSE-CAPES y Programa de Pós-Graduação em Sociologia, UnB.

${ }^{7}$ Se denomina Township a los barrios segregados creados por el apartheid para que vivieran (separadamente) la población clasificada como africana, india o coloured.

${ }^{8}$ Matebeni es activista y académica, aliada de Free Gender.

9 Entre otras, Amina MAMA, 1995; Yvette ABRAHAMS, 1997; Ifi AMADIUME, 1987; Patricia Mc FADDEN, 2003; Desiree LEWIS, 2011
} 
Lewis (201 1 , p. 205) puntualizó la relación entre los mitos de la sexualidad femenina africana y las asociaciones del cuerpo de mujer africana al trabajo brazal y de servicio (doméstico o sexual). La hipersexualización de la mujer negra, estereotipo asociado tanto a las mujeres africanas como afrodescendientes en la diáspora ${ }^{10}$, está vinculada a la construcción de la mujer negra como sexualmente disponible en un contexto de esclavitud y explotación sexual (Pumla Dineo GQOLA, 2006, p. 68-70; Gabeba BADEROON, 2015, p. 87-90). Tal construcción perpetúa la violencia sexual contra las mujeres negras al mismo tiempo que la simboliza como imposible de existir (GQOLA, 2015, p. 21-24). El archivo colonial está plagado de este tipo de representaciones.

En los últimos años de lucha contra el apartheid, diversas organizaciones populares, líderes y movimientos de liberación, discutieron qué hacer con los archivos - sobrevivientes de ese activismo. Muchos de estos acervos son hoy parte de los Robben Is/and - Mayibuye Archives en la University of the Western Cape, UWC. En ellos, cada colección contiene registro de cómo y cuándo fue tomada la decisión política de entregar el acervo a la UWC, institución reconocida por su radicalidad política. En un momento político tan delicado como la formación del primer gobierno negro de Sudáfrica, organizaciones que se preparaban para gobernar el país, también se ocuparon de 'preservar las pruebas' de su existencia.

En los 1990s, en Sudáfrica se multiplicaron las iniciativas rememorativas, trabajo de memoria (Elizabeth JELIN, 2002) y creación de museos y archivos: el Frente Democrático Unido (que aglutinó organizaciones comunitarias entre 1983-90) y la central sindical (COSATU, fundada en 1983) crearon el South African History Arquive (Verne HARRIS, 2002, p. 142) para colocar on-line los registros de las luchas populares; se creó la Comisión de la Verdad y la Reconciliación, el District Six Museum (museo comunitario), el archivo de la memoria oral de la University of Cape Town, entre otras. El archivo, entendido como el control de las representaciones y como un dispositivo productor de existencia, continúa siendo un tema de debate relevante.

Sin embargo, el 'archivo de la liberación' invisibilizó la presencia LGTBI en la lucha: activistas de Free Gender, y mujeres queer ${ }^{11}$ afirman que, si bien las personas queer participaron de 'la lucha'12, no necesariamente se enunciaban como tal (Tandiswa TSHEFU; Sivu Onesipho SIWISA, entrevista 2015; Zethu MATEBENI, 2015, Entrevista). Al respecto, la/el artista Queer Siya Ngcobo declara "¿Qué pensaban? ¿Acaso creían que la lucha era solamente para liberar a los hombres negros cis-género heterosexuales?" 13.

A ello se suma que, en las últimas décadas, diferentes líderes africanos desplegaron en el continente discursos homofóbicos e impulsaron iniciativas de criminalización de la homosexualidad (Sylvia TAMALE, 2011), en una novedosa asociación entre la africaneidad 'ancestral, tradicional, atemporal' y la heterosexualidad obligatoria. En Sudáfrica los discursos homofóbicos públicos asocian su legitimidad a dos adjetivos que califican la homosexualidad como: ungodly y unafrican. Ungodly - contrario a la ley de Dios - apelando al dios cristiano y menos frecuentemente islámico; y unafrican como extranjero y occidental (BBC WORLD NEWS, 2013; SOLDAAT, s/f; Retha BERNADEE, 2015, entrevista).

\footnotetext{
${ }^{10}$ Las relaciones de género y raza en Brasil han sido ampliamente debatida e investigada, destacan intelectuales como Sueli CARNEIRO, 2005; 1995, Luiza BAIRROS, 1995; Lélia GONZÁLEZ; Carlos HASENBALD, 1982; Lélia GONZÁLEZ, 1983; Rita SEGATO, 2007; 2006.

${ }^{11}$ El término queer se utiliza de forma frecuente entre mujeres lesbianas negras de clase media, en ocasiones como autodefinición cercana a disidente sexual, en ocasiones como sinónimo de LGTBI (SIWISA, 2015, entrevista).

${ }^{12}$ Las alusiones repetidas a "la lucha" [contra el apartheid] re-afirman que aún a 22 años de su derrocamiento, quiénes participaron continúan siendo los depositarios legítimos del nuevo régimen.

${ }^{13}$ Siya NGCOBO [nombre artístico: Umlilo], perfil personal de Facebook, 3 junio 2015.
} 
En este contexto político-intelectual, Free Gender junto con Muholi construyen de forma sistemática el archivo visual de las personas LGTBI africanas/negras y sus luchas en Sudáfrica. En el prefacio al libro Faces and Phases, Zanele Muholi menciona que el proyecto original estaba basado en documentar su propia comunidad. Poco a poco ese proyecto creció para transformarse en un archivo visual de la existencia lesbiana en Sudáfrica, en un archivo negro, y en un archivo que también captura la afirmación, diversidad y la belleza de las mujeres negras en abierta disidencia sexual (MUHOLI, 2014, p. 7). La autorepresentación colectiva es una de las tantas formas de contestar un archivo colonial plagado de narrativas orales, escritas y visuales de los cuerpos negros/africanos como "grotescos, no civilizados, y crudamente sexuales" (LEWIS, 2011, p. 199).

A la imagen de cuerpos negros de mujeres lesbianas brutalizados se superponen a las imágenes de mujeres y niñas negras reducidas a ser cuerpos en desintegración, retratadas en el instante post crueldad. La circulación mediática de tales imágenes produce un régimen de visibilidad marcado por la opacidad, donde la víctima sólo puede existir ser percibida - en tanto víctima: "la sociedad te pone etiquetas [...] y ahí pierdes tu identidad como individuo y terminas siendo simplemente otra chica lesbiana" (Nonkululeko Xana NYILENDA, en MUHOLI, 2014, p. 37).

En cambio, el archivo LGTBI en construcción retrata desde el rostro ${ }^{14}$ (Faces and Phases) y la intimidad (Beloved), el reclamo de espacio público (activismo e intervenciones en los Orgullo Gay $^{15}$ ), y de la ley (casamientos y denuncias de crímenes de odio). Producir el archivo visual es una apuesta por la política de los cuerpos y de la mirada. Presenta y propone una disidencia política visual encarnada en texturas corporales, formas de ser mujer y ser negra; una manera distinta de documentar cuerpos y roles disidentes incorporados en miradas, posturas, gestualidades y formas de vestir. Reivindica el registro visual-sensorial por sobre el signo escrito, más asociado al inglés que a las lenguas mayoritarias de la población negra.

El proyecto de crear un acervo LGTBI incluye "hacer existir", retomando el poder talismánico del archivo. "Producir la existencia lesbiana", en palabras de Zanele Muholi, en el documental We live in Fear (2013): "Parece que cada vez que una lesbiana es asesinada nos encontramos, y luego nos volvemos a encontrar en el próximo funeral ¿Qué puedes hacer? Tienes que documentar". El libro de fotografías Faces and Phases es introducido por el poema "Please, Take photographs!" (Sindiwe MAGONA, en MUHOLI, 2014, p. 8), donde el imperativo de fotografiar - documentar, hacer existir - es una respuesta directa al exterminio. "Tómales fotografías, a los niños que no llegarán a tener 30 años / a los niños que nunca... llegarán... a ser adultos". Hacer existir: re-presentar, como si fuese una declaración de guerra abierta contra el exterminio de mujeres negras en disidencia sexual ${ }^{16}$.

Cuando Zanele Muholi y Free Gender buscan producir el archivo LGTBI, existen diversas capas de sentido a las que están contestando: que las personas africanas LGTBI pueden existir y existen; que no son abyectas ni prohibidas, como durante la colonia y el apartheid; que la africaneidad 'verdadera' esté basada en la heterosexualidad obligatoria; que la única forma en que una mujer lesbiana entre en la escena pública es a través de los espectáculos de brutalización, como son retratadas en los medios y en las denuncias de

${ }^{14}$ Faces and Phases presenta retratos de rostro y busto en primera plana, es un desafío abierto a la amenaza de muerte. O una apuesta a la vida, a vivir como colectivo, más allá de la vida y muerte físicas individuales. ${ }^{15}$ En Ciudad del Cabo se realiza la Marcha del Orgullo Gay en febrero en el centro de la ciudad, de orientación mercantilizada, y desde hace 3 años, en mayo se realiza el Orgullo Khumbulani en las comunidades negras.

16 La palabra exterminio no aparece en el activismo local, en cambio se señala recurrentemente la responsabilidad del régimen de supremacía blanca en 'dejar morir' los cuerpos negros.

944 Estudos Feministas, Florianópolis, 24(3): 941-958, setembro-dezembro/2016 
organizaciones 'de buena fe'. El archivo LGTBI pretende contestar la hipervisibilización de mujeres lesbianas como víctimas de crímenes excepcionales; y construye un régimen de visibilidad diferente, que cimienta la normalización e individuación de la existencia lesbiana negra.

\section{Normalizar - Individuar}

De acuerdo a las activistas LGTBI $^{17}$, en sus propias comunidades en los townships, las mujeres africanas lesbianas son estereotipadas como no-normales (fuera de la norma), no africanas, y aliens. Desde el activismo de Free Gender y de Zanele Muholi se busca producir la normalización de la existencia lesbiana, en el campo de las representaciones visuales y de las relaciones sociales, descentrando la diferencia, opacando la disidencia sexual y enfatizando el carácter no definitorio de la sexualidad.

Khumbulani Pride ${ }^{18}$ es un orgullo LGTBI militante, una intervención pública organizada por Free Gender, Gender Dynamix (NGO enfocada en población trans), Triangle Project (población LGTBI negra) y Inclusive Affirmative Ministries (Pastores/as cristianos/as LGTBI). La marcha se desarrolla en las comunidades - de acuerdo a las organizadoras - donde la mayor cantidad de crímenes de odio son cometidos. En 2015, Khumbulani Pride se desarrolló en Khayelitsha: cientos de cuerpos queer, ambiguos y disidentes marcharon $5 \mathrm{~km}$ a pie durante más de dos horas, en un espacio familiar y cotidiano, con sus organizaciones, cantos y temores, bajo la mirada reprobatoria de vecinas/os y la risa nerviosa de los/as niños/as; la marcha produce una visibilización masiva y produce la existencia LGTBI, al tiempo que reclama pertenecer a la comunidad, como LGTBI y como negra/o.

Además de la marcha, las actividades del Khumbulani Pride se extienden durante una semana en la comunidad: realización de debates, exhibición de películas, de foros para concientizar, frenar los crímenes de odio y mejorar la respuesta policial en casos de homofobia. A lo largo del año, Free Gender celebra el Día de la Tradición [Heritage Day], inscribiéndose como africanas; organiza debates en Makhaza Park y The Park, espacios donde los jóvenes se reúnen en fin de semana a socializar y beber; picnics etc. Son formas en las que se reclama el espacio público, y en él, se inscribe la creación y normalización de la existencia lesbiana en sus comunidades.

Muholi fue cofundadora de diversos blogs de activismo LGTBI (Behind the Masks e Inkanyiso ${ }^{19}$ ); fue parte de organizaciones de mujeres negras lesbianas como FEW, Forum of Empowerment of Women, y es una interlocutora de largo plazo de Free Gender. En su trabajo se destacan las exposiciones o series Mo(u)rning (2012, Galeria Stevenson, Ciudad del Cabo), Love and Loss (Febrero 2014, Galeria Stevenson, Johannesburgo), Faces and Phases (2006-2014), y Beloved (2005).

Mo(u)rning se compone de un juego de dos palabras en inglés: Morning, el saludo coloquial de buenos días (abreviación de good morning) y Mourning, que significa estar

\footnotetext{
${ }^{17}$ Esta apreciación se repite en conversaciones públicas e informales y se reiteró en las entrevistas con Funeka SOLDAAT (2014), de Free Gender, Busisiwe NCAYE (2015) de Gender Dynamix; Sindiswa THAFENI de Triangle Project, Zethu MATEBENI (2015), activista LGTBI independiente. Los crímenes de odio en los townships son frecuentemente en espacios públicos, cometidos por perpetradores conocidos por sus víctimas, en ocasiones a la vista de la comunidad.

${ }^{18}$ Khumbulani significa recordar en isixhosa, y se realiza en memoria de las víctimas de crímenes de odio. La marcha en 2015 pasó por esquinas donde fueron perpetrados crímenes contra mujeres negras lesbianas de Khayelitsha.

${ }^{19}$ Inkanyiso es un sitio de activismo fundado en 2006, y conceptualizado por Zanele Muholi. Reúne escritura, poesía y crónicas de personas $L G T B \mid Q$ en inglés, abarcando las más diversas temáticas. Al día de la fecha constituye un enorme archivo virtual de la vida queer en Sudáfrica. Ver THOMAS, 2013; INKANYISO, s/f.
} 
de duelo. La superposición del duelo como un elemento de lo cotidiano constituye una denuncia política, y tiene un paralelismo con el acompañamiento de funerales, crímenes de odio y casos judiciales realizados en Ciudad del Cabo por la organización Free Gender, y por la fotógrafa en diversos lugares del país. La serie Love and Loss [Amor y pérdida] se compone de fotografías de funerales y casamientos LGTBI, ubicándose dentro de la norma social. El llamado matrimonio homosexual es un ritual y un derecho ganado por la comunidad LGTBI sudafricana ${ }^{20}$, único caso en el continente al momento de la realización de la serie ${ }^{21}$.

En Mo(u)rning, la fotógrafa oscila pendularmente entre dos registros de lo político (ver Njabulo NDEBELE, 1991): la denuncia de los crímenes de odio, característico de la literatura de protesta sudafricana; y la ordinaria cotidianeidad politizada en cada pequeña celebración de la vida (desde el 'buenos días' hasta el casamiento), una de las texturas artísticas y políticas que se abren paso en el post-apartheid. En Faces and Phases hay una búsqueda por poblar su gramática visual de rostros negros vivos, particulares, identificables; y por articular la cotideaneidad en la política de mirar a las mujeres negras lesbianas.

Fruto de 8 años de trabajo, Zanele Muholi publica Faces and Phases 2006-2014 en formato de libro, una colección de 226 retratos en blanco y negro de cara y busto de mujeres africanas lesbianas, y algunas personas trans; acompañados de 40 textos narrativos: poesías, historias de vida, militancia, supervivencia y miedo. La colección completa tiene más de 700 retratos, algunos de ellos expuestos por primera vez en 2010, en la Galería Stevenson, Sudáfrica.

El libro mencionado fue presentado en 2015 en la University of Cape Town, un día de invierno a las 18 horas, con frío y noche cerrada ${ }^{22}$. Las calles aledañas, incluso en la seguridad de los suburbios del sur, solo son caminadas por hombres. Por momentos huele como a toque de queda, pero de género. La sala del African Gender Institute está abarrotada de mujeres negras: académicas de clase media y de ONGs se mezclan con estudiantes y activistas comunitarias. La iluminación blanca estridente contrasta con la oscuridad nocturna tan antifeminista del campus universitario. Un grupo de jóvenes butch ${ }^{23} \|$ lega festejando, visten jeans, gorrita, remera y chamarra, con la estética y gestualidad inconfundible de los barrios negros, se sientan en el fondo sobre las mesas, se ríen a carcajadas, exclaman en isiXhosa ${ }^{24}$. Son activistas de Free Gender, fuertes, alegres, sin vergüenza y sin pedir disculpas, nadie diría que son, en su mayoría, sobrevivientes de crímenes de odio (Funeka SOLDAAT, 2014, entrevista). Celebrando la resiliencia lesbiana ${ }^{25}$ es mucho más que una consigna, es una actitud, una necesidad, a veces, un mantra. El clima de festejo sobrepasa las solemnidades que caracterizan a cualquier actividad académica. El libro es una victoria; es entrar y copar un espacio blanco y elitista como la universidad; es desafiar las reglas

\footnotetext{
${ }^{20}$ La Civil Union Act 17, de 2006, reconoce las uniones del mismo sexo. Ello se suma a otros derechos como a la no discriminación por razón de sexo, género u orientación sexual consagrado en la Constitución de 1996; derechos al cambio de sexo o género, y al cambio de nombre; el derecho de los hogares homoparentales a adoptar niños/as (2002).

${ }^{21}$ La mayoría de los países africanos contienen en sus sistemas normativos resabios coloniales que criminalizan la homosexualidad, y otros países aprobaron recientemente. En algunos casos, esas leyes no son aplicadas desde las independencias (INTERNATIONAL LESBIAN AND GAY ASSOCIATION, 2015).

${ }^{22}$ Relato derivado de mi participación personal en el evento, enriquecido con palabras de las activistas, producto de entrevistas, conversaciones o escritos.

${ }^{23}$ Butch es la autoidentificación. Se definen como mujeres de apariencia masculina (principalmente cabello, vestimenta y corporalidad), algunas de ellas también se identifican con roles y formas de socialización que consideran socialmente masculinas.

${ }^{24}$ Lengua hablada por la mayoría de las personas negras de Ciudad del Cabo.

${ }^{25}$ Consigna de la organización, en remeras, panfletos etc.
}

946 Estudos Feministas, Florianópolis, 24(3): 941-958, setembro-dezembro/2016 
generizadas básicas de 'seguridad' para las mujeres ${ }^{26}$; significa - por sobre todas las cosas - definir cómo se desea ser representada, cómo se quiere crear y habitar el archivo LGTBI de la historia sudafricana.

Sentadas a la mesa de debate están las activistas lesbianas Zanele Muholi, Funeka Soldaat y Yonela Nyumbeka. Muholi lleva un sombrero negro sobre su cabello largo de rastas, camisa en colores claros abotonada hasta el cuello y pantalones holgados negros. Funeka Soldaat, como siempre, viste jean, remera, zapatillas y gorrita. Yonela es la más joven, de contextura pequeña y radiante, usa un sombrero de fibras vegetales, pantalones de jean y un aro brillante en la oreja. Zethu Matebeni, académica y activista, coordina la mesa. Antes de que pueda saludar, comienza el toyi-toyi ${ }^{27}$, con una canción de bienvenida para iniciar lo que sería un diálogo de amigas (MATEBENI, 2015, entrevista), no por ello desprovisto de tensiones generacionales (NYUMBEKA, 2014) ${ }^{28}$.

El retrato de Muholi da cuenta de la mujer retratada, de la fotógrafa, y de la relación entre ambas; del momento de intimidad y confianza en el que el mismo es producido. Cada fotografía tiene un profundo sentido de lo individual, un gesto cargado de emociones, tensiones e intensidades: "Yo nunca trabajo con desconocidas. Fotografío personas que conozco" (MUHOLI, 2013). En el documental We live in Fear [Vivimos con miedo], Zanele Muholi acude a KwaThema, (un township) a realizar un retrato de seguimiento a Thumi en su $\operatorname{casa}^{29}$. Comienza a peinarla y hacerle trenzas en el cabello. "La gente me pregunta qué tan influyente soy en el retrato. Y a mí me gusta que las personas se vean bien, se sientan frescas" (MUHOLI, 2013). Durante el proceso de producción del retrato, vemos a Muholi, cámara en mano, en dirección a Thumi recién peinada y en sus mejores ropas, diciéndole "iRespira! Estamos tomando fotos para Faces and Phases, no para la revista de moda".

El retrato de busto y rostro en blanco y negro es un formato altamente estandarizado, incluso una forma de registrar administrativamente la existencia de los/as ciudadanos/as, y de registrar sus fases etarias, para que, en cada momento, sean identificables. En la estandarización, el retrato produce el colectivo - mujeres lesbianas negras - como existente. El retrato ofrece la máxima individuación siendo la parte del cuerpo humano a través de la cual estamos entrenados/as para diferenciar a las personas. En las exposiciones, los retratos son gigantografías de tamaño natural, mientras que en el libro ocupan una página de 30 x $25 \mathrm{~cm}$, lo contrario a una foto carnet, cuya dimensión es la mínima posible distinguible.

El retrato, en este caso, es una apuesta por la identificación, asociada a la individuación multiplicada. En esa individuación participa el contexto: cada fotografía es acompañada del nombre y apellido de la persona, junto con el lugar donde la foto fue tomada. El nombre y apellido, en muchos casos, denotan la pertenencia a un colectivo más amplio. Nombres como Lesego, Betesta, Amogelang, Ayanda, Bathini, Nonkululeko hasta el día de la fecha son solo portados por personas negras en Sudáfrica. Si bien son nombres que pertenecen a lenguas diferentes, todas ellas provienen de alguna de las lenguas africanas. La mayoría de las personas blancas y coloured tienen nombres en

\footnotetext{
${ }^{26}$ Según estas normas, el transporte público es inseguro en la 'noche' (desde las 18h). Impera la antigua imposición racista por la cual la población negra tenía que salir de la ciudad tan pronto termina el horario de trabajo y retirarse a sus ciudades dormitorio.

${ }^{27}$ Toyi-toyi son cantos y bailes asociados a las protestas, introducidos durante la lucha anti-apartheid como parte de la mística, en particular de la lucha armada del Umkhomto we Siswe (el brazo armado del ANC) en la década de 1980.

${ }^{28}$ Conversación pública, en ocasión del lanzamiento del libro Faces \& Phases.

${ }^{29}$ La concepción es romper la temporalidad plana del retrato homogeneizado y testimoniar la profundidad histórica; entendiendo que 'salir de clóset visualmente' es un ejercicio que cambia de persona a persona y en el tiempo.
} 
inglés, afrikáans, o en árabe - si son musulmanes. Los nombres de matriz africana tienen significado elegido por su familia, relacionado con el momento del nacimiento y con ese nuevo ser que nace. Como las lenguas bantu son aglutinantes, un nombre puede reunir lo que traduciríamos como una frase. Los nombres como forma de individuación poseen huellas de un contexto, desde el significado, a la relación con su tronco familiar, a su asociación a una lengua particular, entre otras cosas.

Para las fotos de Ciudad del $\mathrm{Cabo}^{30}$, el espacio viene también cargado de sentidos históricos. Si es un township, si es un suburbio blanco, si se encuentra en áreas urbanizadas o rurales, son marcadores de clase y lingüísticos.

Zanele Muholi, como otras artistas feministas sudafricanas - Penis Siopis, Gabrielle Leroux, Tracey Rose, por ejemplo - trabaja con la agencia performática de los materiales. La fotografía nos provee un fondo, una textura que opera como rastro material del contexto en que la fotografía fue tomada. El retrato de Lumka Stemela, tomado en Nyanga East, Ciudad del Cabo en 2011 (MUHOLI, 2014, p. 133). Nyanga significa Luna en isiXhosa y es uno de los townships negros más antiguos aledaños a la ciudad. Lumka viste una chomba y un jersey, está rapada y tiene el ceño fruncido. El fondo, por sus relieves marcados en luces y sombras, parece la chapa de un container del puerto. En Nyanga, como todos los townships de Ciudad del Cabo, se utilizan containers para comercios - que tienen una estructura rectangular, íntegramente de chapa, de 2,5 por 5 metros, aproximadamente, concentra el frío en invierno y el calor en verano. Lumka, viviendo en Nyanga como una mujer butch, testimonia una época en que "somos libres y no totalmente libres del apartheid" (Pumla GQOLA, 2010, p. 2).

Los textos que acompañan algunos de los retratos visuales colaboran también en la tarea de individuación, presentan recorridos particulares en primera persona, itinerarios de supervivencia y búsqueda de justicia donde se afirma "I am not a Victim, but a Victory" [No soy una Víctima, sino una Victoria] (Lungile DLADLA, en MUHOLI, 2014, p. 166). Las texturas del fondo de cada retrato se proyectan hacia un vocablo, el nombre del lugar donde el retrato fue construido.

En el libro hay retratos localizados en el centro de la ciudad (Green Markef), en townships coloured (Atlhone) donde se encuentra un 10\% de población negra, en distritos multirraciales (GoodWood, Woodstock), o blancos (Muizemberg). Si bien hay una asociación demográfico-estadística entre personas negras y townships en Sudáfrica, la artista también está enfatizando la presencia lesbiana negra en cada rincón de la ciudad, más allá del típico lugar donde se la imagina: expoliada, sin agua potable ni electricidad, sin acceso a sanitarios, violentada cuatro veces, por ser pobre, mujer, negra y lesbiana. Descentrar la existencia negra de los guetos pobres es reclamar para sí la heterogeneidad de la ciudad y sus espacios públicos; es confrontar la articulación estructural (y colonial) entre la ciudad blanca-gueto negro, y las formas en las que estos sitios son transitados, habitados y desafiados por una comunidad LGTBI negra heterogénea.

La colección Faces and Phases está dedicada a documentar la variedad y extensión de la existencia lésbica africana con un proyecto de hipervisibilidad e hiperidentificación. Muchas de las mujeres retratadas asumen una identidad butch, de manera tal que la hipervisibilidad, para muchas de ellas, es un manifiesto cotidiano, que precede el retrato y su publicación ${ }^{31}$. Esa hipervisibilidad es "caminar con un blanco en la espalda todos los días de tu vida" (TSHEFU; SIWISA, 2015, entrevista). Los testimonios en el libro colaboran en la

${ }^{30}$ Me referiré solamente a Ciudad del Cabo porque es la ciudad donde viví y transité un año y medio, de esa forma los lugares mencionados me resultan familiares.

${ }^{31}$ Esto no significa que la mayoría de las mujeres lesbianas negras se autoidentifiquen como butch. 
visualidad del miedo: "temo por mi seguridad, eso es todo" (Bathini DAMBUZA, en MUHOLI, 2014, p. 28) "nunca te puedes sentir libre de ser tu misma por el miedo a ser víctima de un crimen de odio" (NYILENDA, en MUHOLI, 2014, p. 37). El miedo es un elemento de la vida social de las mujeres sudafricanas, a tal punto que la seguridad es uno de los temas principales de las agendas feministas locales desde el fin del apartheid (Glynis RODHES, 2015, entrevista). Free Gender tuvo como slogan del 2014 'Celebrando 20 años de democracia... con miedo', inscripta en la politización feminista de las emociones.

Las personas LGTBI son producidas como excepcionales y 'aliens' o no normales. De ahí la enorme inversión en documentar/producir la existencia lesbiana africana a través de la producción masiva de retratos estandarizados e individuados de mujeres lesbianas y personas trans. El producto (más de 700 retratos) es tan relevante como su proceso de producción a través de las redes del activismo lesbiano en Sudáfrica. La representación de la fotógrafa y la presentación narrativa en primera persona se superponen en la creación del colectivo 'mujeres africanas lesbianas' del cual son parte la fotógrafa y la fotografiada. Ese colectivo sería, sin embargo, construido con base en segregar de tal conjunto a los hombres, a las mujeres blancas y a las mujeres negras heterosexuales. Mujeres lesbianas negras, sociológicamente hablando es no-homogeneizable, pues refiere a una multiplicidad de existencias, situaciones, formas de ser y habitar el mundo (Nonhlanhla MZHIKE, 2010, p. 12-15; MATEBENI, 2015, entrevista).

Siguiendo a Free Gender, la inscripción de la existencia lesbiana dentro de la comunidad es a partir de su condición humana, no de la diferencia que se expresa en la sexualidad: "tenemos sangre y huesos, como ellos, no sé si ellos se dan cuenta. El único detalle es que hacemos cosas diferentes cuando nos vamos a la cama. Pero en la vida cotidiana somos exactamente igual" (SOLDAAT, 2014, entrevista). Y esto se traduce en términos de un activismo LGTBI plenamente interseccional e integrado en las luchas comunitarias y de derechos humanos:

No podemos involucrarnos [solo] en el Khumbulani Pride para ser visibles. Tenemos problemas de agua, de electricidad, tenemos problemas con todo. Hay que tratar de liderar todo, e involucrarse en esas campañas. No se involucren solamente en asuntos LGTBI. Hay que involucrarse en todos los asuntos de la comunidad. (SOLDAAT, 2014, entrevista).

Bajo esta premisa, las activistas de Free Gender se comprometen en las más diversas organizaciones comunitarias. Así también la ONG Triangle trabaja bajo la misma premisa con los grupos LGTBI de las comunidades y reconocen "No es un camino fácil" (Sindiswa THAFENI, 2015, entrevista). Retha Bernadee, de Inclusive Affirmative Ministries indica también que "no queremos ser simplemente toleradas [...] queremos ser incluidas de forma plena, es decir, poder participar de todas las actividades de la iglesia en todas las iglesias, incluso poder ser pastoras" (BERNADEE, 2015, entrevista).

Si bien la identidad LGTBI fue asumida políticamente durante los 1990s como estrategia necesaria para obtener derechos (Mikky VANZYL, 2005, p. 244), esta visión hoy resulta restrictiva y desde las diversas organizaciones se procura recuperar la multidimensionalidad de la vida para confrontar el estereotipo de un ser LGTBI donde la única faceta relevante seria su orientación sexual e identidad de género. La normalización de la existencia lesbiana va de la mano con des-centrar la sexualidad como elemento primordial de la existencia lesbiana, o de la condición humana, tema del siguiente apartado. 


\section{De la denuncia de la muerte a la celebración de la vida}

En los crímenes de odio contra mujeres lesbianas en Sudáfrica la violación sexual es utilizada como arma de humillación, control y destrucción de la víctima y su cuerpo. Dos elementos sobresalen en las frases que las víctimas escuchan de sus perpetradores "te voy a mostrar que eres mujer" (violándote, embarazándote etc.) [Eres lesbiana porque] "nunca conociste a un verdadero hombre" (SOLDAAT, 2014, entrevista; THAFENI, 2015, entrevista) ${ }^{32}$. Como si sólo a través de la violencia sexualizada y de la penetración forzada se produjera el sujeto mujer y el sujeto hombre.

Las denuncias de ONGs, de los medios de comunicación e incluso de algunos trabajos académicos enfatizan este aspecto para movilizar apoyos. De esa manera, inscriben a las mujeres africanas lesbianas como un sujeto colectivo, 'colectivizable', cuya vida y muerte están definidas por su disidencia sexual (mujeres que aman mujeres) y por su vulnerabilidad y condición de víctima, de ser un cuerpo [negro] violable y descartable. Es una víctima cuyos restos son comunicativamente útil al crimen que se cometió contra ella, por los significados de terror y obediencia que proyecta. Estos significados producen dos efectos de jerarquías disciplinadoras.

Por un lado, la violencia sexualizada contra mujeres lesbianas o mujeres en disidencia sexual amplifica un mensaje de heterosexualidad obligatoria. En un contexto donde las relaciones heterosexuales son, para las mujeres, relaciones de alto riesgo. Glynis Rodhes (2015, entrevista), directora de la Red Contra la Violencia contra las Mujeres del Cabo Occidental, indica que, de acuerdo a encuestas oficiales, más del $50 \%$ de las mujeres sudafricanas van a sufrir al menos una violación sexual en sus vidas. El lujo de crueldad perpetrado en grupo y - en ocasiones - en espacios públicos, sobre los cuerpos de mujeres lesbianas se constituye como violencia expresiva, y proyecta los 'peligros' a los márgenes de la heterosexualidad obligatoria. Por otro lado, la violencia contra las mujeres lesbianas no está separada de la violencia que sufren el conjunto de las mujeres negras (MATEBENI, 2015, entrevista) y cuya historicidad es colonial (LEWIS, 2011 ). Bajo el régimen colonial en Sudáfrica, las mujeres negras y asiáticas eran permanentemente violadas como una forma de acrecentar la riqueza de sus amos (prostitución y embarazos forzados) y al mismo tiempo estereotipadas como inviolables (GQOLA, 2015). Durante el apartheid, las mujeres negras permanecieron en la condición jurídica de menores de edad, imposibilitadas de firmar contratos, solicitar créditos etc. Así como los hombres negros, las mujeres fueron cosificadas, consideradas cuerpos consumibles, cuya destrucción violenta es codificada como erótica en la gramática colonial-racista (LEWIS, 201 1, p. 203). Una de las paradojas más dolorosas del racismo es que este estereotipo colonial también se inscribe y reifica a través de la mano de perpetradores negros que forman parte de las mismas comunidades que sus víctimas. Sin embargo, en la cobertura mediática de este tipo de crimen se refuerza la codificación del hombre negro como bestial, mientras se ignora o da por sentado el escenario colonial ${ }^{33}$ donde tales crímenes se inscriben: los townships.

En contestación a la cosificación de los cuerpos femeninos negros, Zanele Muholi produjo series de fotografías tematizando la intimidad lésbica. En la Serie Beloved I, II y III se retrata dos mujeres negras de cabello largo en dreadlocks o rastas, en 3 escenas: en la

\footnotetext{
${ }^{32}$ Los diversos testimonios de sobrevivientes en INKANYISO blog y en los relatos en MUHOLI, 2014 reiteran estas frases.

${ }^{33}$ Utilizo aquí 'colonial' como un adjetivo que denota que la existencia de la segregación racial y económica actual tiene su topos y su génesis en el sistema moderno colonial como fuera definido por Anibal Quijano (2002), y por su explícita relación con la cosificación de la población negra y la voluntad de exterminio expresada en la permanencia de tales guetos.
} 
primera ambas mujeres están con el torso desnudo y una de ellas besa a su compañera en el cuello. En la segunda fotografía una de ellas está recostada, vistiendo un short oscuro, y su compañera, apoyada sobre su cintura y cadera, mira el horizonte en dirección a la cámara. En la tercera fotografía están abrazadas sobre la cama, en el plano de la fotografía solo entran parte de sus torsos y rostro. La fotografía recorta un detalle de un entrelazamiento de cuerpos que está en el fuera de plano. Un recorte de cuerpos que, lejos de las armas de los perpetradores, presupone cuerpos vivos.

En otros trabajos de la fotógrafa, la cristalización de momentos íntimos de diferentes parejas de mujeres negras resulta tan intensamente doméstica que desaparece prácticamente la mirada externa. Quien mira la foto, la cámara y la fotógrafa están invisibilizadas en estas series. No hay una interpelación, a diferencia de la serie Faces \& Phases, donde todos y cada uno de las retratadas mira a cámara-y a los/as observadores/ as de la fotografía - de forma ineludible. El énfasis en la belleza corporal y sus variedades de formas, tonalidades y texturas es una afronta al odio a si misma (self hate, NCAYE, 2015, entrevista; TENGA, 2015, entrevista) cultivado por una sociedad racista y lesbofóbica. Las series que tematizan la intimidad lésbica son una proyección ad infinitum del black is beautiful.

En este lenguaje visual los cuerpos son territorios de placer, en una imagen que captura el erotismo entre dos mujeres negras, en abierta disonancia con los cuerpos de mujeres negras donde otros inscriben significados. Un 'erotismo en si' que no está dedicado a la lente que la fotografía, ni a la fotógrafa, ni a la observadora de la fotografía. Si la imaginación sudafricana está plagada de la visualidad del terror y de la victimización, asociadas al ser-lesbiana-negra, en estas series, el placer sexual, sensual y emocional están naturalizados como parte de una escena de domesticidad totalmente femenina. Son imágenes que también desafían los estereotipos de belleza occidental y los estereotipos occidentalizados de belleza negra, de la mujer de clase media alta híper glamorosa, llena de accesorios, estilizada y con el cabello alisado, prototipo de anuncios comerciales.

Hay una des-colocación de los cuerpos de mujeres negras como víctimas sufrientes (y como fragmentos) hacia una reterritorialización de la agencia. Un descentramiento también del dolor como núcleo de la identidad lésbica y de la negritud. Si esto es así, celebrar la resiliencia lesbiana y documentar la vida en todas sus dimensiones, es un proyecto descolonizador de la existencia material y simbólica de las mujeres negras lesbianas.

\section{Re-presentar: hacia la construcción de un archivo LGTBI}

En el año 2014-15, durante mi estadía y trabajo de campo en Ciudad del Cabo fui confrontada por las más diversas organizaciones sobre la política de las representaciones y la expropiación de las imágenes ${ }^{34}$ : Sisonke SWEAT, el sindicato de trabajadoras sexuales, mantiene un cuidadoso protocolo de autorización para el uso de la palabra o imágenes de sus integrantes, sobre todo relacionado a que la prostitución está ilegalizada en el país. En conversaciones informales, la activista Ruvimbo Tenga cuenta diversas situaciones en que las integrantes de SWEAT fueron damnificadas por serem representadas sin consentimiento en los medios de comunicación, en internet, en trabajos académicos o artísticos. Anne Davis, integrante de la ONG internacional Just Associates, conociendo estas

${ }^{34}$ Lo que estaba en cuestión no era solamente la producción académica como una actividad extractiva, sino también mi condición de clase y raza - universitaria extranjera racializada como blanca. Desde ya que toda mi experiencia de investigación, trabajo y convivencias está inevitablemente mediada por tales situaciones de privilegio. 
tensiones, después de su nombre, me dice "solo hablo por mí misma. Nunca me arrogaría el derecho de representar a alguien" (Anne DAVIS, 2015, entrevista). Pat Fahrenfort indica "antes dejábamos que las mujeres blancas escriban sobre nosotras. Ahora [en el postapartheid] nos dimos cuentas que nosotras podemos escribir nuestra propia historia" (Pat FAHRENFORT, 2015, entrevista).

Sin embargo, la cuestión de si es posible, deseable o legítimo re-presentar, así como la economía política de las re-presentaciones excede, como debate, los ámbitos del activismo y la producción de conocimiento especializado. En el año 2015 circuló en Youtube un video realizado por la fotógrafa negra Andi Mkhosi (Andi MKHOSI, 2015, Documental), habitante del township de Langa. En el video de 12 minutos ella relata visual y oralmente cómo se realizan recorridos turísticos en su barrio: los turistas son blancos y ricos, y los habitantes del barrio visitado son negros y pobres. Estos recorridos son regulados y vendidos como 'una forma de experimentar la verdadera África', constituyen en realidad una convivencia temporaria forzada, desde el punto de vista de las personas locales. Los turistas por lo general acuden con cámaras fotográficas y construyen un sinnúmero de imágenes, retratos obscenos de la 'pobreza'. Incomodados, dos jóvenes fotógrafos negros recorrieron a pie Camps Bay, zona turística y blanca. Tomaron fotografías de actividades cotidianas, como mandar un mensaje de texto, pasear al perro, o caminar. Un tercer integrante filmó el 'safari fotográfico' a la inversa.

El proyecto buscaba confrontar quién tiene derecho a fotografiar a quién, de qué forma una fotografía no consentida es una representación no consentida. Parafraseando a Edward Said (1978), cuando plantea que Oriente fue orientalizado, entre otras cosas, porque podía ser obligado a ser oriental; los/as fotógrafos/as blancos/as 'pueden' tomar una fotografía no consentida en un barrio negro mediados por la estructura de un régimen de supremacía blanca económico y social. Esas fotografías circulan conforme la decisión del/ la fotógrafo/a, usualmente en sus redes sociales, donde se construye y alimenta la narrativa de 'mi viaje a África', con la fotografía como prueba última de una experiencia verdadera. El ángulo, luz y recorte de la fotografía es definido por una mirada turística, visitante, extranjera, encarnada en un cuerpo blanco y con un poder adquisitivo considerablemente mayor al de los habitantes del lugar. Una vez que la fotografía es tomada, la persona fotografiada pierde todo control sobre el ámbito de difusión de la misma. Mientras los turistas extranjeros pueden entrar 'reguladamente' a los barrios negros y re-presentar, cámaras en mano; los fotógrafos negros fueron interpelados, insultados y confrontados por sujetos blancos/as que se sienten agredidos al momento en que son fotografiados sin consentimiento.

Zanele Muholi como fotógrafa negra lesbiana se enclava en ese debate de forma basamental. El consenso sobre la imagen inicia desde el proceso de producción, siendo parte de los colectivos representados en sus series. Las fotografías producen visualmente la existencia del colectivo - mujeres lesbianas negras - y, al mismo tiempo, cada fotografía solo puede existir a través de tal colectivo, cuyas redes le permiten multiplicar las fotografías. Muholi produce un régimen de visibilización que enfatiza y se asienta sobre la capacidad de agencia, es un retrato que se produce en el marco de una relación de amistad, de militancia y de confianza. Pero además en ese régimen de visualización inscribe a las mujeres lesbianas negras en el colectivo 'mujeres': sea con la producción masivas de retratos en blanco y negro; sea con una lente que [no] interviene en las actividades más elementalmente cotidianas como bañarse, recostarse con la pareja o caminar de la mano; sea retratando rituales universalizados como matrimonios y funerales.

En consonancia con las políticas de auto-[re]presentación, en el año 2013, la organización Free Gender publicó el libro Rivers of Life. Lesbian Stories and Poems [Ríos de vida. Poemas y cuentos lésbicos]. El libro, dedicado a "todas las lesbianas que perdieron 
sus vidas por la causa del amor", surgió a partir de un proceso de escritura en talleres facilitado por la feminista Mikki van Zyl. Ella señala "aquí las mujeres lesbianas reclaman la totalidad de sus vidas en sus propios términos" (VAN ZYL, en FREE GENDER, 2013), una colección en la que "la vida y el amor son celebrados" (MATEBENI, en FREE GENDER, 2013). El libro aborda diversos aspectos de la cotidianeidad, eventos e identidades que se definen por la personalidad, cualidades y circunstancias. Las narrativas producidas descentran la sexualidad, no como una vuelta al clóset, sino como una forma de restituir la totalidad de la vida. En las [re]presentaciones se produce el ser mujer lesbiana como ser humano, de ahí que la disidencia sexual es la puerta de entrada como demanda y en simultáneo, estratégicamente marginalizada.

La política de construir imágenes está asociada a las políticas de ver y de mirar, al respecto. En la presentación del libro Faces and Phases en la UCT Yonela Nyumbeka comenta: "Yo me imagino que las personas que ven el libro, ven chicas que se ven como chicos". Y agrega, "quien se tome un poco el trabajo de leerlo entenderá que no es así, que son personas tratando de salir del clóset visualmente, y que a la vez va mucho más allá de eso" 35 . El "mucho más allá de eso" crea nuevas formas de ver, resquebrajando estereotipos ya existentes y mortales.

Tales estereotipos de la mujer lesbiana negra en Sudáfrica tiene varias capas: la primera señala que es inexistente 'no existe la homosexualidad en África' asociada a ella, que es occidental 'la homosexualidad es no africana [un-african], o anti-africana' (por lo tanto no deberían existir); que es contraria a la ley de Dios cristiano (y siendo un pecado, podría ser corregido); y que son 'mujeres que quieren ser hombres' (por ende deberían ser castigadas); $y$, finalmente, 'mujeres que nunca probaron lo que es un hombre verdadero' (es decir que a través de la violación sexual podrían ser restituidas al colectivo de "mujeres normales" heterosexualizadas).

Muholi se involucra y desafía los regímenes que han usado la hipervisibilidad de las mujeres lesbianas negras como una forma de violentarlas, como por ejemplo las coberturas sensacionalistas de los crímenes de odio (GQOLA, 2006, p. 84). Las mujeres lesbianas africanas ocupan espacio en los periódicos locales y nacionales cuando sufren ataques lesbofóbicos. Son noticias de cuerpos lastimados, violentados, asesinados, humillados, en general por grupos de hombres jóvenes. Así, la construcción mediática unilateral de la mujer lesbiana africana es de una mujer genérica y victimizada, una mujer en abstracto que es definida por su sexualidad y por la violencia brutal que se ejerce contra ella - en la narrativa dominante - 'a causa de su sexualidad'.

Zanele Muholi propone un régimen de visibilización donde las formas en que las mujeres lesbianas negras son presentadas y representadas está altamente controlado, consensuado y políticamente evaluado, un dialecto de documentación " tal como lo definió LEWIS (2005, p. 14, en GQOLA, 2006, p. 85). Un dialecto de documentación desde el que contestar la violación sexual y la violencia como un lenguaje (Pumla GQOLA, 2015, p. 22) que se inscribe en la anulación simbólica a través de la desintegración de los cuerpos negros lésbicos.

Por ejemplo, entre los diversos testimonios de Faces and Phases hay formas de identificación variadas y ambiguas como mujer, Lesego Twale, con cabello corto y camisa de mangas, con un gesto endurecido y mirada intensa, dice:

No me veo como un hombre. No actúo como un hombre y no quiero ser un hombre. Soy una mujer y la forma en que me veo, actúo, vivo y amo, es como lo hace una mujer.

${ }^{35}$ NYUMBEKA, 2014, declaración hecha durante la conversación pública en el lanzamiento del libro Faces \& Phases, de Zanele MUHOLI, 2014. 
Soy diferente de muchas mujeres, y muchas mujeres son diferentes de mí. Reconozco esto y celebro las diferencias cuando me enuncio como butch" (Lesego TWALE, en MUHOLI, 2014, p. 235).

"Desde que tengo memoria soy un tomboy" (Amogelang SENOKWANE, en MUHOLI, 2014 , p. 19); "Yo me visto, camino y actúo como lo que muchas personas entienden que lo hace un chico. Pero aun así, tengo un gran orgullo de ser mujer" (NYILENDA, en MUHOLI, 2014 , p. 37) "Yo no soy Butch, yo no soy Femme. Yo soy yo" (DAMBUZA, en MUHOLI, 2014, p. 28). En una forma particular y articulada de entenderse y posicionarse como mujer en un mundo heteronormado, las participantes de Faces and Phases revelan en sus historias, corporalidad y autodefiniciones, infinitas maneras individuales de ser mujer, lesbiana y negra en Sudáfrica.

\section{Conclusión}

En el presente texto se analizó las formas en que el art-ivismo de Muholi y la acciones de Free Gender están entrelazadas en la producción del archivo LGTBI como proyección de la existencia lesbiana. El archivo LGTBI, en primer lugar, documenta la existencia de un colectivo cuyas integrantes están en permanente amenaza de muerte, sea por asesinatos de odio/violaciones correctivas, por la pobreza o HIV (Funeka SOLDAAT, s/f, documental Ndim, Ndim); en consonancia, Free Gender produce hechos documentables: eventos, marchas, debates, picnics, e incorpora activistas a la actividad de documentación visual. En la organización de tales hechos, crea la existencia lesbiana negra, el colectivo y activismo a través del cual existir, simbólica y materialmente. En segundo lugar, documenta la existencia de un colectivo forzado a la invisibilidad/anulación simbólica como agentes, como mujeres particulares con historias diversas ${ }^{36}$, tanto en el archivo colonial como en el de la liberación nacional. Free Gender se inscribe entre las activistas que lucharon y luchan contra la supremacía blanca, no solo por las prácticas de interseccionalidad político-ideológica, también en la estética y mística. En tercer lugar, Muholi y Free Gender documentan desde la experiencia vivida como sustrato teórico del activismo, escapando de la otrificacion (Zanele MUHOLI, 2013, documental We Live in Fear) de las representaciones a través de la auto-presentación. En la construcción del archivo LGTBI, la creación de un acervo visual cuenta por el resultado y por el proceso de su producción: el proceso habilita el control y consenso sobre las re-presentaciones visuales. Como resultado, el archivo LGTBI es la afirmación de una existencia que trasciende y habita la eliminación física. En consonancia, es la celebración de la resiliencia lésbica, de la vida cotidiana, del amor, de la intimidad como espacio de individuación. Una intimidad que, aunque retratada, existe en sí y para sí.

\section{Referencias}

ABRAHAMS, Yvette. "Colonialism, Disjunctures and Disfunction: Sarah Baartman's Resistance (remix)". Agenda, v. 58, p. 12-25, 2003.

AMADIUME, Ifi. Male Daughters, Female Husbands. London: Zed Press, 1987.

BADEROON, Gabeba. Regarding Muslims: From Slavery to Post-apartheid. Johannesburgo: Witwatersrand University Press, 2016.

BAIRROS, Luiza. "Nossos feminismos revisitados". Revista Estudos Feministas, v. 3, n. 2, p. 458463, 1995.

${ }^{36}$ Yonela NYEMBEKA, conversación pública durante el lanzamiento del libro Faces \& Phases, 2014. 
CARNEIRO, Sueli. "Ennegrecer el feminismo. La situación de la mujer negra en América Latina desde una perspectiva de género". Nouvelles Quéstions Féministes. Revue Internationale francophone, v. 24, n. 2, p. 21-22, 2005.

. "Gênero, Raça e Ascenção Social". Revista Estudos Feministas, v. 3, n. 2, p. 544-552, 1995.

CEJAS, Mónica Inés. "Cultura, poder y representación en la disputa por la inclusión. Sexualidades en Sudáfrica post-apartheid." In: (Coord.). Feminismo, cultura y política: prácticas irreverentes. México: UAM-X, 2016 (en prensa).

CRENSHAW, Kimberley. "Documento para o encontro de Especialistas em aspectos da discriminação racial relativos ao gênero". Revista Estudos Feministas, v. 10, n. 1, p. 171 $188,2002$.

DAGNINO, Evelina. "Dimensions of citizenship in contemporary Brazil". Fordham Law Review, v. 75, n. 5, p. 2469-2482, abril 2007.

DAVIS, Angela. Mujeres, raza y clase. Madrid: Ediciones Akal, 1981.

GONZÁLEZ, Lélia. "Racismo e sexismo na cultura brasileira". In: SILVA, Luiz Antônio Machado et al. Movimentos sociais urbanos, minorias étnicas e outros estudos. Brasília: ANPOCS (Ciências Sociais Hoje, 2), p. 223-244, 1983.

GONZÁLEZ, Lélia; HASENBALG, Carlos. Lugar de negro. Rio de Janeiro: Marco Zero, 1982.

GQOLA, Pumla Dineo. Rape. The South African Nightmare. Cidade do Cabo: MF Books Joburg, 2015.

What is slavery to me. Poscolonial/ slave memory in post apartheid South Africa. Johannesburg: Wits University Press, 2010.

. "Through Zanele Muholi's eyes: Re/imagining ways of seeing Black lesbians". In: MUHOLI, Zanele. Only half the picture. Ciudad del Cabo: Michael Stevenson STE. 2006, p. 82-89.

HARRIS, Verne. "The archival sliver: a perspective on the construction of social memory in archives and the transition from apartheid to democracy". In: HAMILTON, Carolyn (Ed.). Refiguring the archive. Cape Town: David Phillip Ed., 2002, p. 135-151.

HAMILTON, Carolyn et al. "Introduction". In: HAMILTON, Carolyn (Ed.). Refiguring the archive. Cape Town: David Phillip Ed., 2002, p. 7-18.

JELIN, Elizabeth. Los trabajos de la memoria. Madrid: Siglo XXI, 2002.

LEWIS, Desiree. "Representing African Sexualities". In: TAMALE, Sylvia (Ed.). African sexualities. A reader. Kenia: Pambazuka Editores, 2011 , p. 199-216.

MAMA, Amina. Beyond the masks. Race Gender and Subjetivity. USA/Canada: Routledge, 1995.

MARINDO, Ravayi et al. The State of the Population in the Western Cape Province. Cidade do Cabo: HSRC, 2008.

MBEMBE, Achille. "The power of the archives and its limits". In: HAMILTON, Carolyn (Ed.). Refiguring the archive. Ciudad del Cabo: David Phillip, 2002, p. 19-24.

Mc FADDEN, Patricia. "Sexual Pleasure as Feminist Choice". Feminist Africa, v. 2, p. 50-60, 2003.

MKHIZE, Nonhlanlha et al. The country we want to live in, Hate crimes and homophobia in the lives of black lesbian South Africans. Ciudad del Cabo: HSRC Press, 2010.

MUHOLI, Zanele Faces + Phases 2006-14. Alemania: Stidler Publishers, 2014. Only half the picture. Ciudad del Cabo: Michael Stevenson STE, 2006.

OLDFIELD, Sophie; SALO, Elaine. "Nurturing researchers, building local knowledge, the body politics project”. Feminist Africa, v. 13, p. 87-94, diciembre 2009.

QUIJANO, Aníbal. "Colonialidad del poder, eurocentrismo y América Latina". In: LANDER, Edgardo (Comp.) La colonialidad del saber: eurocentrismo y ciencias sociales. 
Perspectivas Latinoamericanas. Buenos Aires, Argentina: CLACSO, Consejo Latinoamericano de Ciencias Sociales, julio 2000, p 122-151.

SAID, Edward W. Orientalismo. O Oriente como invenção do Ocidente. São Paulo: Schwartz, 1978.

SEGATO, Rita Laura. La Nación y sus Otros. Raza, etnicidad y diversidad religiosa en tiempos de política de la identidad. Buenos Aires: Prometeo, 2007.

"O Édipo brasileiro: a dupla negação de gênero e raça". Série Antropologia, v. 400, Departamento de Antropologia, Universidade de Brasília, 2006.

TAMALE, Sylvia. "Researching and theorising sexualities in Africa". In: TAMALE, Sylvia (Ed.) African sexualities. A reader, Kenia: Pambazuka Editores, 2011, p. 11-36.

THOMAS, Kylie. "Profile: Digital Visual activism: A profile of Inkanyso". Feminist Africa v. 18, p. 79-81, diciembre 2013.

VANZYL, Mikki. "Escaping Heteronormative Bondage, Sexuality in Citizenship". In: GOUWS, Amanda (Ed.). (Un) Thinking Citizenship. Feminist Debates in Contemporary South Africa, Ciudad del Cabo: UCT Press, 2005, p. 223-252.

\section{Entrevistas}

BERNADEE, Retha, 18 de Julio 2015. Observatory. Integrante de Inclussive Affirmative Ministries. Pastora no ordenada a causa de su orientación sexual.

DEYI, Busisiwe Ncaye, Julio 2015., Observatory. Asistente jurídica e Investigadora de Gender Dinamix (ONG enfocada en personas trans).

MATEBENI, Zethu, 20 Noviembre 2015. Hidding Campus UCT, Centro. Profesora investigadora en el Centre of Humanities, UCT; activista negra y queer, aliada de Free Gender.

RODHES, Glynis, 13 de Noviembre de 2015. Observatory. Staff de la Western Cape Network Against Violence Against Women [Red contra la violencia contra las mujeres del Western Cape].

SIWISA, Sivu Onesipho; TSHEFU, Sandiswa, Noviembre 2015. Observatory, Activistas LGTBI.

Tandiswa TSHEFU; Sivu Onesipho SIWISA, entrevista 2015; Zethu MATEBENI, 2015, Entrevista. (Todas las otras entrevistas fueron realizadas como parte de mi trabajo de campo de doctorado en Ciudad del Cabo, Sudáfrica).

TENGA, Ruvimbo, marzo 2015, Observatory. Encargada de Medios y comunicación de Sisonke SWEAT (Sindicato de Trabajadorxs Sexuales) y migrante de Zimbawe.

THAFENI, Sindiswa, Julio 2015, Mowbray. Staff de Triangle Project y activista feminista.

\section{Documentales}

BBC WORLD NEWS. "Is Homosexuality un-African" [TV Program]. Johannesburgo, Sudáfrica, 2010 [Re-emitido por South African Broadcasting Corporation en "The Big Debate" en 2013]. Disponible en: https://www.youtube.com/watch?v=xL7EIO4IOv8. Acceso en 03/ $10 / 2015$.

MUHOLI, Zanele. "We live in Fear", [documental corto, dirigido por Fairfax Zanele Muholi, 2013. Disponible en: http://mg.co.za/multimedia/2013-11-26-zanele-muholi-we-live-infear. Acceso en 10/01/2016.

. "Enraged by the picture", [documental corto part 2, $3.30 \mathrm{~min}$ ] (s/f). Disponible en: https:/ $/ w w w$. youtube $. c o m / w a t c h ? v=p M X O C K P 6 L q c \& l i s t=P L B 3 D 19 E D O B A B A B 14 F \&$ index $=9$. Acceso en 10/01/2016.

"Difficult Love" [Programa de televisión, 55 minutos] 2013. Disponible en: https:// $w w w$.youtube.com/watch? $v=$ gUoDcLqoQP4. Acceso en 10/01/2016.

SOLDAAT, Funeka (s/f). "Ndim, Ndim (It's me, it's me)". Disponible en: https://www.youtube.com/ watch?v=D-ncFD2QxTw. Acceso en 10/01/2016.

956 Estudos Feministas, Florianópolis, 24(3): 941-958, setembro-dezembro/2016 
(14 Abril 2012) "I am a Women", programa especial de Leap Of Faith, SABC, [TV program Season 1, Episode 2, Act I]. Disponible en: https://www.youtube.com/ watch?v=DTCejdvGFiA, Act II https://www.youtube.com/watch?v=DTCejdvGFiA. Acceso en 10/12/2015.

MKHOSI, Andi. "Camps Bay Suburb (Alternative Township) Tour". 2015 [Documental, 12 min. Ciudad del Cabo]. Disponible en: https://www.youtube.com/watch?v=8HotFI7LhNo. Acceso en 15/01/2016.

\section{Documentos electrónicos}

GLOBAL LEGAL RESEARCH CENTRE. "Laws on Homosexuality in African Nations", 2014. Disponible en http://www.loc.gov/law/help/criminal-laws-on-homosexuality/homosexuality-laws-inafrican-nations.pdf. Acceso en 10/12/2015.

HAITH, Chelsea. "Enough is kwanele for Gay Pride", The Journalist, Ciudad del Cabo: Mayo, 2015. Disponible en: http://www.thejournalist.org.za/spotlight/enough-is-kwanele-for-gaypride. Acceso en 10/12/2015.

INTERNATIONAL LESBIAN AND GAY ASSOCIATION. "79 Countries were homosexuality is llegal". 2015. Disponible en: http://76crimes.com/76-countries-where-homosexuality-is-illegal/. Acceso en 10/12/2015.

MAREGELE, Bárbara. Most people unsafe in Khayelitsha, Surrey shows. Ciudad del Cabo: Ground Up website, 17 de diciembre de 2015. Disponible en http://groundup.org.za/ article/most-people-feel-unsafe-khayelitsha-survey-shows 3607. Acceso en 10/02/2016.

ROBERTS, Cheryl. Middle Class/ professional women Activist must be Authentic about their Activism. Blog de Cheryl Roberts. African women warrior Cheryl Roberts, 2015. Disponible en: https://africanwomanwarrior.wordpress.com/2015/02/16/middle-classprofessionalwomen-activists-must-be-authentic-about-activism-by-cheryl-roberts-2/. Acceso en 10/ $12 / 2015$.

SEFALI, Pharie. "'This is what Pride should be!' - Gays and lesbians march through Khayelitsha" Ciudad del Cabo: Ground Up website, 18 de mayo de 2015. Disponible en: http:// groundup.org.za/article/what-pride-should-be-gays-and-lesbians-march-throughkhayelitsha_2948. Acceso en 10/12/2015.

"Gays and lesbians will march in Khayelitsha". South African Breaking News, 14 de mayo de 2015. Disponible en: http://www.sabreakingnews.co.za/2015/05/14/gays-andlesbians-will-march-in-khayelitsha/. Acceso en 10/12/2015.

\section{Sitios web}

CAPE TOWN PRIDE. Página de internet. Disponible en: http://www.capetownpride.org/ FREEGENDER BLOG. Disponible en www.freegender.wordpress.com. Acceso en 10/12/2015. FREE GENDER KHAYELITSHA, Página de Facebook. Em: https://www.facebook.com/ freegender.gender?fref $=$ ts. Acceso en 10/12/2015.

INKHANYSO. Página de internet. Disponible en: http://inkanyiso.org/about/. Acceso en 10/12/2015. KHUMBULANI PRIDE. Página de Facebook. Disponible en: https://www.facebook.com/ Khumbulani-LGBTI-Pride-1403022153354164/. Acceso en 10/12/2015.

ROBERTS, Cheryl. Página de Facebook. Disponible en: https://www.facebook.com/ cheryl.roberts.9828?fref $=$ ts. Acceso en 10/12/2015.

SISONKE SWEAT Página de Facebook. En: https://www.facebook.com/Sisonke-144299332431443/ ?fref $=$ ts. Acceso en 15/07/2015.

[Recebido em 02/05/2016

e aceito para publicação em 18/05/2016] 


\section{Normalizar a existencia lésbica}

Resumo: O presente artigo analisa as ressonâncias entre o ativismo de Free Gender organização de mulheres negras lésbicas (Khayelitsha, Cidade do Cabo) e o art-ivismo LGTBI de Zanele Muholi (África do Sul). Discute-se quais são os recursos utilizados para a produção artesanal da existência lésbica, a sua normalização e individuação: de um lado, as participações e intervenções públicas de Free Gender nos espaços comunitários; e do outro, a produção de retratos e de cenas da intimidade - as séries fotográficas de Zanele Muholi Faces and Phases e Beloved. Por último, sublinha-se a dimensão subversiva de fundar o arquivo LGTBI e contestar o arquivo colonial com as suas múltiplas representações estereotipadas das sexualidades das mulheres negras.

Palavras-chove: Ativismo LGTBI; Mulheres negras; Sexualidade; Arquivo.

\section{Normalizing Black Lesbian Existence}

Abstract: The article analises how Free Gender activism - a black lesbians' organization from Khayelitsha, Cape Town - and Zanele Muholi's art-ivism (South Africa) are intertwined in handcrafting, normalizing and individualizing black lesbian existences. How Free Gender public interventions and its participation in community structures is in a productive dialogue with the massive production of portraits and intimacy scenes in Muholi's photography (Phases and Faces and Beloved Series). How this two projects collaborate to produce new regimes of visuality, involving the politics of looking, and challenging the colonial archive and its stereotyped representations of black women sexualities.

Keywords: LGTBI activism; Black women; Sexuality; Archive. 